\title{
Gallbladder Adenoma
}

National Cancer Institute

\section{Source}

National Cancer Institute. Gallbladder Adenoma. NCI Thesaurus. Code C7720.

A polypoid epithelial neoplasm that arises from the gallbladder. According to the neoplastic growth pattern, it is classified as tubular, tubulopapillary, or papillary. 